\title{
A regularization method for treating zero points of the sum of two monotone operators
}

\author{
Xiaolong Qin', Sun Young Cho² and Lin Wang ${ }^{3 *}$
}

"Correspondence:

w164mail@aliyun.com

${ }^{3}$ College of Statistics and

Mathematics, Yunnan University of

Finance and Economics, Kunming, 650221, China

Full list of author information is available at the end of the article

\begin{abstract}
In this paper, a regularization method for treating zero points of the sum of two monotone operators is investigated. Strong convergence theorems are established in the framework of Hilbert spaces.
\end{abstract}

Keywords: maximal monotone operator; fixed point; nonexpansive mapping; proximal point algorithm; zero point

\section{Introduction}

In the real world, many important problems have reformulations which require finding zero points of some nonlinear operator, for instance, evolution equations, complementarity problems, mini-max problems, variational inequalities and optimization problems; see [1-13] and the references therein. It is well known that minimizing a convex function $f$ can be reduced to finding zero points of the subdifferential mapping $A=\partial f$. Splitting methods have recently received much attention due to the fact that many nonlinear problems arising in applied areas such as image recovery, signal processing, and machine learning are mathematically modeled as a nonlinear operator equation and this operator is decomposed as the sum of two nonlinear operators. The central problem is to iteratively find a zero point of the sum of two monotone operators; that is, $0 \in(A+B)(x)$. Many problems can be formulated as a problem of the above form. For instance, a stationary solution to the initial value problem of the evolution equation $0 \in F u+\frac{\partial u}{\partial t}, u_{0}=u(0)$, can be recast as the above inclusion problem when the governing maximal monotone $F$ is of the form $F=A+B$; for more details; see [14] and the references therein.

In this paper, we study a regularization method for treating zero points of the sum of an inverse-strongly monotone and a maximal monotone operator. The main contribution of the paper is establish a strong convergence theorem for viscosity zero points under mild restrictions imposed on the control sequences. The main results include the corresponding results in $\mathrm{Xu}$ [15] as a special case. The organization of this paper is as follows. In Section 2, we provide some necessary preliminaries. In Section 3, a regularization method is investigated. A strong convergence theorem for zero points of the sum operator is established. In Section 4, applications of the main results are discussed.

\section{Preliminaries}

In what follows, we always assume that $H$ is a real Hilbert space with inner product $\langle\cdot, \cdot\rangle$ and norm $\|\cdot\|$. Let $C$ be a nonempty, closed and convex subset of $H$. Let $S: C \rightarrow C$ be a

( 2014 Qin et al.; licensee Springer. This is an Open Access article distributed under the terms of the Creative Commons Attribution License (http://creativecommons.org/licenses/by/2.0), which permits unrestricted use, distribution, and reproduction in any medium, provided the original work is properly cited. 
mapping. $F(S)$ stands for the fixed point set of $S$; that is, $F(S):=\{x \in C: x=S x\}$. Recall that $S$ is said to be contractive iff there exists a constant $\kappa \in(0,1)$ such that

$$
\|S x-S y\| \leq \kappa\|x-y\|, \quad \forall x, y \in C .
$$

It is well known that every contractive mapping has a unique fixed point in metric spaces. $S$ is said to be nonexpansive iff

$$
\|S x-S y\| \leq\|x-y\|, \quad \forall x, y \in C .
$$

If $C$ is a bounded, closed, and convex subset of $H$, then $F(S)$ is not empty, closed, and convex; see [16] and the references therein.

Let $A: C \rightarrow H$ be a mapping. Recall that $A$ is said to be monotone iff

$$
\langle A x-A y, x-y\rangle \geq 0, \quad \forall x, y \in C .
$$

Recall that $A$ is said to be inverse-strongly monotone iff there exists a constant $\alpha>0$ such that

$$
\langle A x-A y, x-y\rangle \geq \alpha\|A x-A y\|^{2}, \quad \forall x, y \in C .
$$

For such a case, $A$ is also said to be $\alpha$-inverse-strongly monotone. It is not hard to see that every inverse-strongly monotone mapping is monotone and continuous.

Recall that a set-valued mapping $B: H \rightrightarrows H$ is said to be monotone iff, for all $x, y \in H$, $f \in B x$ and $g \in B y$ imply $\langle x-y, f-g\rangle>0$. In this paper, we use $B^{-1}(0)$ to stand for the zero point of $B$. A monotone mapping $B: H \rightrightarrows H$ is maximal iff the graph $\operatorname{Graph}(B)$ of $B$ is not properly contained in the graph of any other monotone mapping. It is well known that a monotone mapping $B$ is maximal if and only if, for any $(x, f) \in H \times H,\langle x-y, f-g\rangle \geq 0$, for all $(y, g) \in \operatorname{Graph}(B)$ implies $f \in B x$. For a maximal monotone operator $B$ on $H$, and $r>0$, we may define the single-valued resolvent $J_{r}: H \rightarrow \operatorname{Dom}(B)$, where $\operatorname{Dom}(B)$ denote the domain of $B$. It is well known that $J_{r}$ is firmly nonexpansive, and $B^{-1}(0)=F\left(J_{r}\right)$.

Recently, many authors studied zero points of monotone operators based on different regularization methods; see [17-29] and the references therein. The main motivation is from $\mathrm{Xu}$ [15]. We propose a regularization method for treating zero points of the sum of two monotone operators. Strong convergence theorems are established in the framework of Hilbert spaces.

In order to prove our main results, we also need the following lemmas.

Lemma 2.1 [30] Let $A: C \rightarrow H$ be a mapping, and $B: H \rightrightarrows H$ a maximal monotone operator. Then $F\left(J_{r}(I-r A)\right)=(A+B)^{-1}(0)$.

Lemma 2.2 [31] Let $\left\{a_{n}\right\}$ be a sequence of nonnegative numbers satisfying the condition $a_{n+1} \leq\left(1-t_{n}\right) a_{n}+t_{n} b_{n}+c_{n}, \forall n \geq 0$, where $\left\{t_{n}\right\}$ is a number sequence in $(0,1)$ such that $\lim _{n \rightarrow \infty} t_{n}=0$ and $\sum_{n=0}^{\infty} t_{n}=\infty,\left\{b_{n}\right\}$ is a number sequence such that $\lim _{\sup _{n \rightarrow \infty}} b_{n} \leq 0$, and $\left\{c_{n}\right\}$ is a positive number sequence such that $\sum_{n=0}^{\infty} c_{n}<\infty$. Then $\lim _{n \rightarrow \infty} a_{n}=0$.

Lemma 2.3 [32] Let $H$ be a Hilbert space, and $A$ a maximal monotone operator. For $\lambda>0$, $\mu>0$, and $x \in E$, we have $J_{\lambda} x=J_{\mu}\left(\frac{\mu}{\lambda} x+\left(1-\frac{\mu}{\lambda}\right) J_{\lambda} x\right)$, where $J_{\lambda}=(I+\lambda A)^{-1}$ and $J_{\mu}=(I+\mu A)^{-1}$. 


\section{Main results}

Theorem 3.1 Let $A: C \rightarrow H$ be an $\alpha$-inverse-strongly monotone mapping and let $B$ be $a$ maximal monotone operator on $H$. Assume that $\operatorname{Dom}(B) \subset C$ and $(A+B)^{-1}(0)$ is not empty. Let $f: C \rightarrow C$ be a fixed $\kappa$-contraction and let $J_{r_{n}}=\left(I+r_{n} B\right)^{-1}$. Let $\left\{x_{n}\right\}$ be a sequence in $C$ in the following process: $x_{0} \in C$ and

$$
\left\{\begin{array}{l}
y_{n}=\alpha_{n} f\left(x_{n}\right)+\left(1-\alpha_{n}\right) x_{n}, \\
x_{n+1}=J_{r_{n}}\left(y_{n}-r_{n} A y_{n}+e_{n}\right), \quad \forall n \geq 0,
\end{array}\right.
$$

where $\left\{\alpha_{n}\right\}$ is a real number sequence in $(0,1),\left\{e_{n}\right\}$ is sequence in $H$ and $\left\{r_{n}\right\}$ is a positive real number sequence in $(0,2 \alpha)$. If the control sequences satisfy the following restrictions:

(a) $\lim _{n \rightarrow \infty} \alpha_{n}=0, \sum_{n=0}^{\infty} \alpha_{n}=\infty$ and $\sum_{n=1}^{\infty}\left|\alpha_{n}-\alpha_{n-1}\right|<\infty$;

(b) $0<a \leq r_{n} \leq b<2 \alpha$ and $\sum_{n=1}^{\infty}\left|r_{n}-r_{n-1}\right|<\infty$;

(c) $\sum_{n=0}^{\infty}\left\|e_{n}\right\|<\infty$,

then $\left\{x_{n}\right\}$ converges strongly to a point $\bar{x} \in(A+B)^{-1}(0)$, where $\bar{x}=\operatorname{Proj}_{(A+B)^{-1}(0)} f(\bar{x})$.

Proof First, we show that $\left\{x_{n}\right\}$ is bounded. Notice that $I-r_{n} A$ is nonexpansive. Indeed, we have

$$
\begin{aligned}
\left\|\left(I-r_{n} A\right) x-\left(I-r_{n} A\right) y\right\|^{2} \\
\quad=\|x-y\|^{2}-2 r_{n}\langle x-y, A x-A y\rangle+r_{n}{ }^{2}\|A x-A y\|^{2} \\
\quad \leq\|x-y\|^{2}-r_{n}\left(2 \alpha-r_{n}\right)\|A x-A y\|^{2} .
\end{aligned}
$$

In view of the restriction (b), we find that $I-r_{n} A$ is nonexpansive. Fixing $p \in(A+B)^{-1}(0)$, we find that

$$
\left\|y_{n}-p\right\| \leq \alpha_{n}\left\|f\left(x_{n}\right)-p\right\|+\left(1-\alpha_{n}\right)\left\|x_{n}-p\right\| \leq\left(1-\alpha_{n}(1-\kappa)\right)\left\|x_{n}-p\right\|+\alpha_{n}\|f(p)-p\| .
$$

It follows that

$$
\begin{aligned}
\left\|x_{n+1}-p\right\| & \leq\left\|\left(y_{n}-r_{n} A y_{n}+e_{n}\right)-\left(I-r_{n} A\right) p\right\| \\
& \leq\left\|\left(I-r_{n} A\right) y_{n}-\left(I-r_{n} A\right) p\right\|+\left\|e_{n}\right\| \\
& \leq\left(1-\alpha_{n}(1-\kappa)\right)\left\|x_{n}-p\right\|+\alpha_{n}\|f(p)-p\|+\left\|e_{n}\right\| \\
& \leq \max \left\{\left\|x_{n}-p\right\|, \frac{\|f(p)-p\|}{1-\kappa}\right\}+\left\|e_{n}\right\| \\
& \leq \max \left\{\left\|x_{n-1}-p\right\|, \frac{\|f(p)-p\|}{1-\kappa}\right\}+\left\|e_{n-1}\right\|+\left\|e_{n}\right\| \\
& \vdots \\
& \leq \max \left\{\left\|x_{0}-p\right\|, \frac{\|f(p)-p\|}{1-\kappa}\right\}+\sum_{i=0}^{n}\left\|e_{i}\right\| \\
& \leq \max \left\{\left\|x_{0}-p\right\|, \frac{\|f(p)-p\|}{1-\kappa}\right\}+\sum_{i=0}^{\infty}\left\|e_{i}\right\|<\infty .
\end{aligned}
$$


This proves that the sequence $\left\{x_{n}\right\}$ is bounded, and so is $\left\{y_{n}\right\}$. Notice that

$$
\left\|y_{n}-y_{n-1}\right\| \leq\left(1-\alpha_{n}(1-\kappa)\right)\left\|x_{n}-x_{n-1}\right\|+\left|\alpha_{n}-\alpha_{n-1}\right|\left\|f\left(x_{n-1}\right)-x_{n-1}\right\| .
$$

Putting $z_{n}=y_{n}-r_{n} A y_{n}+e_{n}$, we find that

$$
\begin{aligned}
\left\|z_{n}-z_{n-1}\right\| \leq & \left\|y_{n}-y_{n-1}\right\|+\left\|r_{n}-r_{n-1}\right\|\left\|A y_{n-1}\right\|+\left\|e_{n}\right\|+\left\|e_{n-1}\right\| \\
\leq & \left(1-\alpha_{n}(1-\kappa)\right)\left\|x_{n}-x_{n-1}\right\|+\left|\alpha_{n}-\alpha_{n-1}\right|\left\|f\left(x_{n-1}\right)-x_{n-1}\right\| \\
& +\left|r_{n}-r_{n-1}\right|\left\|A y_{n-1}\right\|+\left\|e_{n}\right\|+\left\|e_{n-1}\right\| .
\end{aligned}
$$

It follows from Lemma 2.3 that

$$
\begin{aligned}
\left\|x_{n+1}-x_{n}\right\| & =\left\|J_{r_{n}} z_{n}-J_{r_{n-1}} z_{n-1}\right\| \\
& =\left\|J_{r_{n-1}}\left(\frac{r_{n-1}}{r_{n}} z_{n}+\left(1-\frac{r_{n-1}}{r_{n}}\right) J_{r_{n}} z_{n}\right)-J_{r_{n-1}} z_{n-1}\right\| \\
& \leq\left\|\frac{r_{n-1}}{r_{n}}\left(z_{n}-z_{n-1}\right)+\left(1-\frac{r_{n-1}}{r_{n}}\right)\left(J_{r_{n}} z_{n}-z_{n-1}\right)\right\| \\
& \leq\left\|\left(z_{n}-z_{n-1}\right)+\left(1-\frac{r_{n-1}}{r_{n}}\right)\left(J_{r_{n}} z_{n}-z_{n}\right)\right\| \\
& \leq\left\|z_{n}-z_{n-1}\right\|+\frac{\left|r_{n}-r_{n-1}\right|}{a}\left\|J_{r_{n}} z_{n}-z_{n}\right\| \\
& \leq\left(1-\alpha_{n}(1-\kappa)\right)\left\|x_{n}-x_{n-1}\right\|+f_{n},
\end{aligned}
$$

where

$$
f_{n}=\left|\alpha_{n}-\alpha_{n-1}\right|\left\|f\left(x_{n-1}\right)-x_{n-1}\right\|+\left|r_{n}-r_{n-1}\right|\left(\left\|A y_{n-1}\right\|+\frac{\left\|J_{r_{n}} z_{n}-z_{n}\right\|}{a}\right)+\left\|e_{n}\right\|+\left\|e_{n-1}\right\| .
$$

It follows from the restrictions (a), (b), and (c) that $\sum_{n=1}^{\infty} f_{n}<\infty$. In view of Lemma 2.2, we find that $\lim _{n \rightarrow \infty}\left\|x_{n+1}-x_{n}\right\|=0$. In view of $\left\|y_{n}-x_{n}\right\| \leq \alpha_{n}\left\|f\left(x_{n}\right)-x_{n}\right\|$, we find from the above that

$$
\lim _{n \rightarrow \infty}\left\|y_{n}-x_{n+1}\right\|=\lim _{n \rightarrow \infty}\left\|y_{n}-x_{n}\right\|=0
$$

Next, we show that

$$
\limsup _{n \rightarrow \infty}\left\langle f(\bar{x})-\bar{x}, y_{n}-\bar{x}\right\rangle \leq 0
$$

where $\bar{x}$ is the unique fixed point of the mapping $\operatorname{Proj}_{(A+B)^{-1}(0)} f$. To show this inequality, we choose a subsequence $\left\{y_{n_{i}}\right\}$ of $\left\{y_{n}\right\}$ such that

$$
\limsup _{n \rightarrow \infty}\left\langle f(\bar{x})-\bar{x}, y_{n}-\bar{x}\right\rangle=\lim _{i \rightarrow \infty}\left\langle f(\bar{x})-\bar{x}, y_{n_{i}}-\bar{x}\right\rangle \leq 0
$$

Since $\left\{y_{n_{i}}\right\}$ is bounded, we find that there exists a subsequence $\left\{y_{n_{i_{j}}}\right\}$ of $\left\{y_{n_{i}}\right\}$ which converges weakly to $\hat{x}$. Without loss of generality, we can assume that $y_{n_{i}} \rightarrow \hat{x}$. 
Now, we show that $\hat{x} \in(A+B)^{-1}(0)$. Notice that $y_{n}-r_{n} A y_{n}+e_{n} \in x_{n+1}+r_{n} B x_{n+1}$; that is,

$$
\frac{y_{n}-r_{n} A y_{n}+e_{n}-x_{n+1}}{r_{n}} \in B x_{n+1} \text {. }
$$

Let $\mu \in B v$. Since $B$ is monotone, we find that

$$
\left\langle\frac{y_{n}+e_{n}-x_{n+1}}{r_{n}}-A y_{n}-\mu, x_{n+1}-v\right\rangle \geq 0 .
$$

In view of the restriction (b), we see from (3.1) that $\langle-A \hat{x}-\mu, \hat{x}-v\rangle \geq 0$. This implies that $-A \hat{x} \in B \hat{x}$, that is, $\hat{x} \in(A+B)^{-1}(0)$. This proves that (3.2) holds. Notice that

$$
\begin{gathered}
\left\|y_{n}-\bar{x}\right\|^{2} \leq \alpha_{n} \kappa\left\|x_{n}-\bar{x}\right\|\left\|y_{n}-\bar{x}\right\|+\alpha_{n}\left\langle f(\bar{x})-\bar{x}, y_{n}-\bar{x}\right\rangle \\
+\left(1-\alpha_{n}\right)\left\|x_{n}-\bar{x}\right\|\left\|y_{n}-\bar{x}\right\| .
\end{gathered}
$$

It follows that $\left\|y_{n}-\bar{x}\right\|^{2} \leq\left(1-\alpha_{n}(1-\kappa)\right)\left\|x_{n}-\bar{x}\right\|^{2}+2 \alpha_{n}\left\langle f(\bar{x})-\bar{x}, y_{n}-\bar{x}\right\rangle$. On the other hand, we have

$$
\begin{aligned}
\left\|x_{n+1}-\bar{x}\right\|^{2} \leq & \left\|J_{r_{n}}\left(y_{n}-r_{n} A y_{n}+e_{n}\right)-\bar{x}\right\|^{2} \\
\leq & \left\|\left(y_{n}-r_{n} A y_{n}\right)-\left(I-r_{n} A\right) \bar{x}\right\|^{2} \\
& \quad+\left\|e_{n}\right\|\left(\left\|e_{n}\right\|+2\left\|\left(y_{n}-r_{n} A y_{n}\right)-\left(I-r_{n} A\right) \bar{x}\right\|\right) \\
\leq & \left\|y_{n}-\bar{x}\right\|^{2}+\left\|e_{n}\right\|\left(\left\|e_{n}\right\|+2\left\|\left(y_{n}-r_{n} A y_{n}\right)-\left(I-r_{n} A\right) \bar{x}\right\|\right) \\
\leq & \left(1-\alpha_{n}(1-\kappa)\right)\left\|x_{n}-\bar{x}\right\|^{2}+2 \alpha_{n}\left\langle f(\bar{x})-\bar{x}, y_{n}-\bar{x}\right\rangle \\
& +\left\|e_{n}\right\|\left(\left\|e_{n}\right\|+2\left\|\left(y_{n}-r_{n} A y_{n}\right)-\left(I-r_{n} A\right) \bar{x}\right\|\right) .
\end{aligned}
$$

An application of Lemma 2.2 to the above inequality yields $\lim _{n \rightarrow \infty}\left\|x_{n}-\bar{x}\right\|=0$. This completes the proof.

\section{Applications}

First, we consider the problem of finding a minimizer of a proper convex lower semicontinuous function.

For a proper lower semicontinuous convex function $g: H \rightarrow(-\infty, \infty]$, the subdifferential mapping $\partial g$ of $g$ is defined by

$$
\partial g(x)=\left\{x^{*} \in H: g(x)+\left\langle y-x, x^{*}\right\rangle \leq g(y), \forall y \in H\right\}, \quad \forall x \in H
$$

Rockafellar [33] proved that $\partial g$ is a maximal monotone operator. It is easy to verify that $0 \in \partial g(v)$ if and only if $g(v)=\min _{x \in H} g(x)$.

Theorem 4.1 Let $g: H \rightarrow(-\infty,+\infty]$ be a proper convex lower semicontinuous function such that $(\partial g)^{-1}(0)$ is not empty. Let $f: H \rightarrow H$ be a $\kappa$-contraction and let $\left\{x_{n}\right\}$ be a sequence in $H$ in the following process: $x_{0} \in H$ and

$$
\left\{\begin{array}{l}
y_{n}=\alpha_{n} f\left(x_{n}\right)+\left(1-\alpha_{n}\right) x_{n}, \\
x_{n+1}=\arg \min _{z \in H}\left\{g(z)+\frac{\left\|z-y_{n}-e_{n}\right\|^{2}}{2 r_{n}}\right\}, \quad \forall n \geq 0,
\end{array}\right.
$$


where $\left\{\alpha_{n}\right\}$ is a real number sequence in $(0,1),\left\{e_{n}\right\}$ is sequence in $H$ and $\left\{r_{n}\right\}$ is a positive real number sequence. If the control sequences satisfy the following restrictions:

(a) $\lim _{n \rightarrow \infty} \alpha_{n}=0, \sum_{n=0}^{\infty} \alpha_{n}=\infty$ and $\sum_{n=1}^{\infty}\left|\alpha_{n}-\alpha_{n-1}\right|<\infty$;

(b) $0<a \leq r_{n}$;

(c) $\sum_{n=0}^{\infty}\left\|e_{n}\right\|<\infty$,

then $\left\{x_{n}\right\}$ converges strongly to a point $\bar{x} \in(\partial g)^{-1}(0)$, where $\bar{x}=\operatorname{Proj}_{(\partial g)^{-1}(0)} f(\bar{x})$.

Proof Since $g: H \rightarrow(-\infty, \infty]$ is a proper convex and lower semicontinuous function, we see that subdifferential $\partial g$ of $g$ is maximal monotone. Noting that

$$
x_{n+1}=\arg \min _{z \in H}\left\{g(z)+\frac{\left\|z-y_{n}-e_{n}\right\|^{2}}{2 r_{n}}\right\}
$$

is equivalent to

$$
0 \in \partial g\left(x_{n+1}\right)+\frac{1}{r_{n}}\left(x_{n+1}-y_{n}-e_{n}\right) .
$$

It follows that

$$
y_{n}+e_{n} \in x_{n+1}+r_{n} \partial g\left(x_{n+1}\right) .
$$

Putting $A=0$, we immediately derive from Theorem 3.1 the desired conclusion.

Next, we consider the problem of finding a solution of a classical variational inequality.

Let $C$ be a nonempty closed and convex subset of a Hilbert space $H$. Let $i_{C}$ be the indicator function of $C$, that is,

$$
i_{C}(x)= \begin{cases}0, & x \in C, \\ \infty, & x \notin C .\end{cases}
$$

Since $i_{C}$ is a proper lower and semicontinuous convex function on $H$, the subdifferential $\partial i_{C}$ of $i_{C}$ is maximal monotone. So, we can define the resolvent $J_{r}$ of $\partial i_{C}$ for $r>0$, i.e., $J_{r}:=\left(I+r \partial i_{C}\right)^{-1}$. Letting $x=J_{r} y$, we find that

$$
\begin{aligned}
y \in x+r \partial i_{C} x & \Longleftrightarrow y \in x+r N_{C} x \\
& \Longleftrightarrow\langle y-x, v-x\rangle \leq 0, \quad \forall v \in C \\
& \Longleftrightarrow x=\operatorname{Proj}_{C} y,
\end{aligned}
$$

where $\operatorname{Proj}_{C}$ is the metric projection from $H$ onto $C$ and $N_{C} x:=\{e \in H:\langle e, v-x\rangle, \forall v \in C\}$.

Theorem 4.2 Let $A: C \rightarrow H$ be an $\alpha$-inverse-strongly monotone mapping. Assume that $V I(C, A)$ is not empty. Let $f: C \rightarrow C$ be a fixed $\kappa$-contraction. Let $\left\{x_{n}\right\}$ be a sequence in $C$ in the following process: $x_{0} \in C$ and

$$
\left\{\begin{array}{l}
y_{n}=\alpha_{n} f\left(x_{n}\right)+\left(1-\alpha_{n}\right) x_{n}, \\
x_{n+1}=\operatorname{Proj}_{C}\left(y_{n}-r_{n} A y_{n}+e_{n}\right), \quad \forall n \geq 0,
\end{array}\right.
$$


where $\left\{\alpha_{n}\right\}$ is a real number sequence in $(0,1),\left\{e_{n}\right\}$ is sequence in $H$ and $\left\{r_{n}\right\}$ is a positive real number sequence in $(0,2 \alpha)$. If the control sequences satisfy the following restrictions:

(a) $\lim _{n \rightarrow \infty} \alpha_{n}=0, \sum_{n=0}^{\infty} \alpha_{n}=\infty$ and $\sum_{n=1}^{\infty}\left|\alpha_{n}-\alpha_{n-1}\right|<\infty$;

(b) $0<a \leq r_{n} \leq b<2 \alpha$ and $\sum_{n=1}^{\infty}\left|r_{n}-r_{n-1}\right|<\infty$;

(c) $\sum_{n=0}^{\infty}\left\|e_{n}\right\|<\infty$,

then $\left\{x_{n}\right\}$ converges strongly to a point $\bar{x} \in \operatorname{VI}(C, A)$, where $\bar{x}=\operatorname{Proj}_{V I(C, A)} f(\bar{x})$.

Proof Putting $B=\partial i_{C}$ in Theorem 3.1, we find that $J_{r_{n}}=\operatorname{Proj}_{C}$. We can draw the desired conclusion from Theorem 3.1.

Next, we consider the problem of finding a solution of a Ky Fan inequality, which is known as an equilibrium problem in the terminology of Blum and Oettli; see [34] and [35] and the references therein.

Let $F$ be a bifunction of $C \times C$ into $\mathbb{R}$, where $\mathbb{R}$ denotes the set of real numbers. Recall the following equilibrium problem:

Find $x \in C$ such that $F(x, y) \geq 0, \quad \forall y \in C$.

To study the equilibrium problem (4.1), we may assume that $F$ satisfies the following restrictions:

(A1) $F(x, x)=0$ for all $x \in C$;

(A2) $F$ is monotone, i.e., $F(x, y)+F(y, x) \leq 0$ for all $x, y \in C$;

(A3) for each $x, y, z \in C$, $\lim \sup _{t \downarrow 0} F(t z+(1-t) x, y) \leq F(x, y)$;

(A4) for each $x \in C, y \mapsto F(x, y)$ is convex and lower semicontinuous.

The following lemma can be found in [35].

Lemma 4.3 Let $F: C \times C \rightarrow \mathbb{R}$ be a bifunction satisfying (A1)-(A4). Then, for any $r>0$ and $x \in H$, there exists $z \in C$ such that $F(z, y)+\frac{1}{r}\langle y-z, z-x\rangle \geq 0, \forall y \in C$. Further, define

$$
T_{r} x=\left\{z \in C: F(z, y)+\frac{1}{r}\langle y-z, z-x\rangle \geq 0, \forall y \in C\right\}
$$

for all $r>0$ and $x \in H$. Then (1) $T_{r}$ is single-valued and firmly nonexpansive; (2) $F\left(T_{r}\right)=$ $E P(F)$ is closed and convex.

Lemma 4.4 [36] Let $F$ be a bifunction from $C \times C$ to $\mathbb{R}$ which satisfies (A1)-(A4), and let $A_{F}$ be a multivalued mapping of $H$ into itself defined by

$$
A_{F} \mathcal{X}= \begin{cases}\{z \in H: F(x, y) \geq\langle y-x, z\rangle, \forall y \in C\}, & x \in C, \\ \emptyset, & x \notin C .\end{cases}
$$

Then $A_{F}$ is a maximal monotone operator with the domain $D\left(A_{F}\right) \subset C, E P(F)=A_{F}^{-1}(0)$, where $F P(F)$ stands for the solution set of (4.1), and $T_{r} x=\left(I+r A_{F}\right)^{-1} x, \forall x \in H, r>0$, where $T_{r}$ is defined as in (4.2).

Theorem 4.5 Let $F: C \times C \rightarrow \mathbb{R}$ be a bifunction satisfying (A1)-(A4). Assume that $E P(F)$ is not empty. Let $f: C \rightarrow C$ be a fixed $\kappa$-contraction and let $T_{r_{n}}=\left(I+r_{n} A_{F}\right)^{-1}$. Let $\left\{x_{n}\right\}$ be 
a sequence in $C$ in the following process: $x_{0} \in C$ and

$$
x_{n+1}=T_{r_{n}}\left(\alpha_{n} f\left(x_{n}\right)+\left(1-\alpha_{n}\right) x_{n}+e_{n}\right), \quad \forall n \geq 0,
$$

where $\left\{\alpha_{n}\right\}$ is a real number sequence in $(0,1),\left\{e_{n}\right\}$ is sequence in $H$ and $\left\{r_{n}\right\}$ is a positive real number sequence. If the control sequences satisfy the following restrictions:

(a) $\lim _{n \rightarrow \infty} \alpha_{n}=0, \sum_{n=0}^{\infty} \alpha_{n}=\infty$ and $\sum_{n=1}^{\infty}\left|\alpha_{n}-\alpha_{n-1}\right|<\infty$;

(b) $0<a \leq r_{n} \leq b<\infty$ and $\sum_{n=1}^{\infty}\left|r_{n}-r_{n-1}\right|<\infty$;

(c) $\sum_{n=0}^{\infty}\left\|e_{n}\right\|<\infty$,

then $\left\{x_{n}\right\}$ converges strongly to a point $\bar{x} \in E P(F)$, where $\bar{x}=\operatorname{Proj}_{E P(F)} f(\bar{x})$.

Proof Putting $A=0$ in Theorem 3.1, we find that $J_{r_{n}}=T_{r_{n}}$. From Theorem 3.1, we can draw the desired conclusion immediately.

Recall that a mapping $T: C \rightarrow T$ is said to be $\alpha$-strictly pseudocontractive if there exists a constant $\alpha \in[0,1)$ such that

$$
\|T x-T y\|^{2} \leq\|x-y\|^{2}+\alpha\|(I-T) x-(I-T) y\|^{2}, \quad \forall x, y \in C .
$$

The class of strictly pseudocontractive mappings was first introduced by Browder and Petryshyn [37]. It is well known that if $T$ is $\alpha$-strictly-pseudocontractive, then $I-T$ is $\frac{1-\alpha}{2}$-inverse-strongly monotone.

Finally, we consider fixed point problem of $\alpha$-strictly pseudocontractive mappings.

Theorem 4.6 Let $T: C \rightarrow C$ be an $\alpha$-strictly pseudocontractive mapping with a nonempty fixed point set and let $f: C \rightarrow C$ be a fixed $\kappa$-contraction. Let $\left\{x_{n}\right\}$ be a sequence generated in the following manner: $x_{0} \in C$ and

$$
\left\{\begin{array}{l}
y_{n}=\alpha_{n} f\left(x_{n}\right)+\left(1-\alpha_{n}\right) x_{n}, \\
x_{n+1}=\left(1-r_{n}\right) y_{n}+r_{n} T y_{n}, \quad \forall n \geq 0,
\end{array}\right.
$$

where $\left\{\alpha_{n}\right\}$ is a real number sequence in $(0,1)$ and $\left\{r_{n}\right\}$ is a positive real number sequence in $(0,1-\alpha)$. If the control sequences satisfy the following restrictions:

(a) $\lim _{n \rightarrow \infty} \alpha_{n}=0, \sum_{n=0}^{\infty} \alpha_{n}=\infty$ and $\sum_{n=1}^{\infty}\left|\alpha_{n}-\alpha_{n-1}\right|<\infty$;

(b) $0<a \leq r_{n} \leq b<1-\alpha$ and $\sum_{n=1}^{\infty}\left|r_{n}-r_{n-1}\right|<\infty$;

then $\left\{x_{n}\right\}$ converges strongly to a point $\bar{x} \in F(T)$, where $\bar{x}=\operatorname{Proj}_{F(T)} f(\bar{x})$.

Proof Putting $A=I-T$, we find $A$ is $\frac{1-\alpha}{2}$-inverse-strongly monotone. We also have $F(T)=$ $V I(C, A)$ and $\operatorname{Proj}_{C}\left(y_{n}-r_{n} A y_{n}\right)=\left(1-r_{n}\right) y_{n}+r_{n} T y_{n}$. In view of Theorem 3.1, we obtain the desired result. 


\section{Author details}

${ }^{1}$ Department of Mathematics, Hangzhou Normal University, Hangzhou, 310036, China. ${ }^{2}$ Department of Mathematics, Gyeongsang National University, Jinju, 6660-701, Korea. ${ }^{3}$ College of Statistics and Mathematics, Yunnan University of Finance and Economics, Kunming, 650221, China.

\section{Acknowledgements}

The authors are grateful to the three anonymous referees for useful suggestions, which improved the contents of the article.

Received: 5 December 2013 Accepted: 11 March 2014 Published: 25 Mar 2014

\section{References}

1. Kinderlehrer, D, Stampacchia, G: An Introduction to Variational Inequalities and Their Applications. Academic Press, New York (1980)

2. Facchinei, F, Pang, JS: Finite-Dimensional Variational Inequalities and Complementarity Problems. Springer, New York (2003)

3. Kamimura, S, Takahashi, W: Weak and strong convergence of solutions to accretive operator inclusions and applications. Set-Valued Anal. 8, 361-374 (2000)

4. Cho, SY, Qin, X, Kang, SM: Iterative processes for common fixed points of two different families of mappings with applications. J. Glob. Optim. 57, 1429-1446 (2013)

5. Cho, SY, Li, W, Kang, SM: Convergence analysis of an iterative algorithm for monotone operators. J. Inequal. Appl. 2013, Article ID 199 (2013)

6. Cho, SY, Kang, SM: Approximation of common solutions of variational inequalities via strict pseudocontractions. Acta Math. Sci. 32, 1607-1618 (2012)

7. Wang, Z, Lou, W: A new iterative algorithm of common solutions to quasi-variational inclusion and fixed point problems. J. Math. Comput. Sci. 3, 57-72 (2013)

8. Wu, C: Mann iteration for zero theorems of accretive operators. J. Fixed Point Theory 2013, Article ID 3 (2013)

9. Qin, X, Su, Y: Approximation of a zero point of accretive operator in Banach spaces. J. Math. Anal. Appl. 329, 415-424 (2007)

10. Zegeye, $\mathrm{H}$, Shahzad, N: Strong convergence theorem for a common point of solution of variational inequality and fixed point problem. Adv. Fixed Point Theory 2, 374-397 (2012)

11. Kim, JK: Strong convergence theorems by hybrid projection methods for equilibrium problems and fixed point problems of the asymptotically quasi- $\phi$-nonexpansive mappings. Fixed Point Theory Appl. 2011, Article ID 10 (2011)

12. Yang, S: Zero theorems of accretive operators in reflexive Banach spaces. J. Nonlinear Funct. Anal. 2013, Article ID 2 (2013)

13. Qin, $X$, Cho, YJ, Kang, SM: Convergence theorems of common elements for equilibrium problems and fixed point problems in Banach spaces. J. Comput. Appl. Math. 225, 20-30 (2009)

14. Lions, PL, Mercier, B: Splitting algorithms for the sum of two nonlinear operators. SIAM J. Numer. Anal. 16, 964-979 (1979)

15. Xu, HK: A regularization method for the proximal point algorithm. J. Glob. Optim. 36, 115-125 (2006)

16. Browder, FE: Nonlinear operators and nonlinear equations of evolution in Banach spaces. Proc. Symp. Pure Math. 18 78-81 (1976)

17. Qin, X, Cho, SY, Wang, L: Iterative algorithms with errors for zero points of $m$-accretive operators. Fixed Point Theory Appl. 2013, Article ID 148 (2013)

18. Hao, Y: Zero theorems of accretive operators. Bull. Malays. Math. Soc. 34, 103-112 (2011)

19. Bruck, RE Jr.: A strongly convergent iterative method for the solution of $0 \in U x$ for a maximal monotone operator $U$ in Hilbert space. J. Math. Anal. Appl. 48, 114-126 (1974)

20. Yuan, Q, Cho, SY: Proximal point algorithms for zero points of nonlinear operators. Fixed Point Theory Appl. 2014 Article ID 42 (2014)

21. Qin, X, Su, Y: Strong convergence theorems for relatively nonexpansive mappings in a Banach space. Nonlinear Anal. 67, 1958-1965 (2007)

22. Qin, X, Cho, SY, Kang, SM: Iterative algorithms for variational inequality and equilibrium problems with applications. J. Glob. Optim. 48, 423-445 (2010)

23. $\mathrm{Wu}, \mathrm{C}, \mathrm{Lv}, \mathrm{S}$ : Bregman projection methods for zeros of monotone operators. J. Fixed Point Theory 2013, Article ID 7 (2013)

24. Cho, SY, Qin, X, Kang, SM: Hybrid projection algorithms for treating common fixed points of a family of demicontinuous pseudocontractions. Appl. Math. Lett. 25, 854-857 (2012)

25. Cho, SY, Kang, SM: Zero point theorems for $m$-accretive operators in a Banach space. Fixed Point Theory 13,49-58 (2012)

26. Chen, JW, Wan, Z, Zou, Y: Strong convergence theorems for firmly nonexpansive-type mappings and equilibrium problems in Banach spaces. Optimization 62, 483-497 (2013)

27. Cho, SY, Kang, SM: Approximation of fixed points of pseudocontraction semigroups based on a viscosity iterative process. Appl. Math. Lett. 24, 224-228 (2011)

28. Kamimura, S, Takahashi, W: Approximating solutions of maximal monotone operators in Hilbert spaces. J. Approx. Theory 106, 226-240 (2000)

29. Kang, SM, Cho, SY, Liu, Z: Convergence of iterative sequences for generalized equilibrium problems involving inverse-strongly monotone mappings. J. Inequal. Appl. 2010, Article ID 827082 (2010)

30. Cho, SY: Strong convergence of an iterative algorithm for sums of two monotone operators. J. Fixed Point Theory 2013, Article ID 6 (2013)

31. Liu, L: Ishikawa and Mann iterative process with errors for nonlinear strongly accretive mappings in Banach spaces. J. Math. Anal. Appl. 194, 114-125 (1995)

32. Barbu, V: Nonlinear Semigroups and Differential Equations in Banach Space. Noordhoff, Groningen (1976) 
33. Rockafellar, RT: Characterization of the subdifferentials of convex functions. Pac. J. Math. 17, 497-510 (1966)

34. Fan, K: A minimax inequality and applications. In: Shisha, O (ed.) Inequality. III, pp. 103-113. Academic Press, New York (1972)

35. Blum, E, Oettli, W: From optimization and variational inequalities to equilibrium problems. Math. Stud. 63, 123-145 (1994)

36. Takahashi, S, Takahashi, W, Toyoda, M: Strong convergence theorems for maximal monotone operators with nonlinear mappings in Hilbert spaces. J. Optim. Theory Appl. 147, 27-41 (2010)

37. Browder, FE, Petryshyn, WV: Construction of fixed points of nonlinear mappings in Hilbert space. J. Math. Anal. Appl. 20, 197-228 (1967)

10.1186/1687-1812-2014-75

Cite this article as: Qin et al.: A regularization method for treating zero points of the sum of two monotone operators. Fixed Point Theory and Applications 2014, 2014:75

Submit your manuscript to a SpringerOpen ${ }^{\circ}$ journal and benefit from:

- Convenient online submission

- Rigorous peer review

- Immediate publication on acceptance

- Open access: articles freely available online

- High visibility within the field

- Retaining the copyright to your article 